07

\title{
Фотовольтаические характеристики светодиодов на основе AIGaAs
}

\section{(C) A.A. Соколовский}

Фрязинский фрилиал института радиотехники и электроники им. В.А. Котельникова РАН, Фрязино, Московская обл., Россия

E-mail: asokol@list.ru

Поступило в Редакцию 13 декабря 2017 г.

Исследованы фотовольтаические характеристики более 20 типов светодиодов, излучающих в диапазоне $830-970 \mathrm{~nm}$. Показано, что полупроводниковые структуры $\mathrm{Al}_{x} \mathrm{Ga}_{1-x} \mathrm{As}$, применяемые для изготовления таких светодиодов, могут использоваться также для изготовления фотовольтаических преобразователей монохроматического излучения с достаточно высоким КПД.

DOI: 10.21883/PJTF.2018.08.45967.17154

Известно [1-3], что светодиоды на основе AlGaAs могут работать в качестве фотовольтаических преобразователей монохроматического излучения. На основе таких преобразователей могут быть созданы простые и достаточно эффективные системы питания электронных схем оптическим излучением, что является перспективным для создания помехозащищенных измерительных систем [4,5].

В настоящей работе были проведены исследования фотовольтаических характеристик светодиодов на основе структур $\mathrm{Al}_{x} \mathrm{Ga}_{1-x} \mathrm{As}$, предназначенных для генерации излучения в диапазоне длин волн 800-970 nm.

Были исследованы фотовольтаические характеристики светодиодов различных типов (АЛ107А, АЛ108А, АЛ115, АЛ118, АЛ156, АЛ157, L34F3C, L34SF4C, L34SF7BT, L34SF7C, L53SF4C, L53F3BT, L53SF6C, L53SF7BT, SE5450-014, TSAL4400, TSAL5100, TSAL6100, TSFF5210-01, TSFF5210-02 и др.).

На рис. 1 приведены характерные спектры излучения и фоточувствительности семи типов светодиодов.

Из приведенных спектров видно, что максимум чувствительности светодиодов в фотовольтаическом режиме смещен относительно линии 

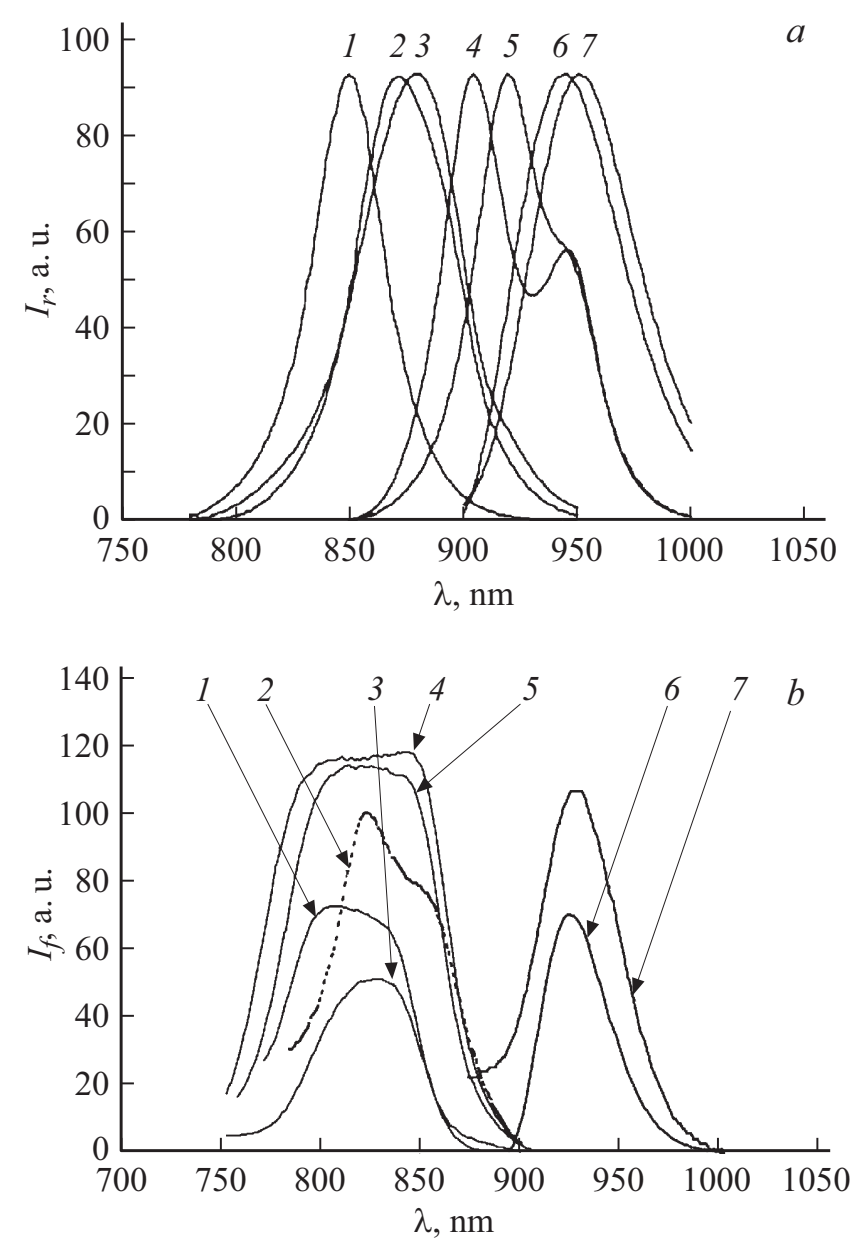

Рис. 1. Характерные спектры излучения $(a)$ и фоточувствительности $(b)$ семи различных светодиодов на основе $\mathrm{Al}_{x} \mathrm{Ga}_{1-x}$ As. 1 - L34SF7C, 2 -АЛ157, 3 - АЛ118, 4 - АЛ108А, 5 - АЛ156, 6 - АЛ115, 7 - АЛ107А.

излучения на $30-50 \mathrm{~nm}$ в сторону более коротких волн. Это соотношение характерно для всех исследованных образцов светодиодов на основе $\mathrm{Al}_{x} \mathrm{Ga}_{1-x} \mathrm{As}$ независимо от типа и производителя. Так,

Письма в ЖТФ, 2018, том 44, вып. 8 
например, для светодиодов с длиной волны излучения 850-870 nm (что характерно для чистого GaAs в активной области) максимум фоточувствительности лежит в области $800-830 \mathrm{~nm}$. У светодиодов АЛ107А, АЛ115 за счет сильного легирования активной области спектр излучения смещен до $950 \mathrm{~nm}$, а максимум фоточувствительности лежит в диапазоне 900-910 $\mathrm{nm}$.

Более детально в настоящей работе исследованы фотовольтаические параметры более 50 образцов светодиодов АЛ118 из разных партий. В качестве источника излучения использовался полупроводниковый лазер с длиной волны $808 \mathrm{~nm}$ и мощностью излучения в многомодовом волокне до $1 \mathrm{~W}$. Излучение на светодиод подавалось с помощью многомодового оптического волокна с диаметром световедущей жилы $62.5 \mu \mathrm{m}$. Светодиоды предварительно отбирались по максимальному значению тока короткого замыкания $I_{s c}$, который зависит не только от особенностей полупроводниковой структуры, но и от формы электродов, которые оптимизированы для светодиодного режима работы, погрешностей изготовления внешней линзы и других факторов. Для уменышения потерь излучения часть линзы светодиода сошлифовывалась, после чего волокно юстировалось относительно фоточувствительной площадки для достижения максимального тока короткого замыкания и приклеивалось к светодиоду оптическим клеем. При таком способе ввода излучения в фотовольтаический преобразователь плотность мощности составляет более $3000 \mathrm{~W} / \mathrm{cm}^{2}$ (при входной мощности $100 \mathrm{~mW}$ ), что может приводить к локальному перегреву структуры и требует обеспечения эффективного теплоотвода. Характерное напряжение холостого хода $V_{o c}$ фотовольтаических преобразователей на основе светодиодов из $\mathrm{Al}_{x} \mathrm{Ga}_{1-x} \mathrm{As}$ составляет при комнатной температуре $1.26 \pm 0.02 \mathrm{~V}$. При изменении температуры напряжение $V_{\text {oc }}$ линейно изменяется от $1.35 \pm 0.02 \mathrm{~V}$ (при $-60^{\circ} \mathrm{C}$ ) до $1.21 \pm 0.02 \mathrm{~V}\left(\right.$ при $\left.+60^{\circ} \mathrm{C}\right)$. Среднее значение тока короткого замыкания $I_{s c}$ в этом же диапазоне температур при оптической мощности 140-150 mW составляло $50 \pm 10 \mathrm{~mA}$, причем максимальное значение $I_{s c}$ достигается в диапазоне температур от -20 до $+30^{\circ} \mathrm{C}$.

Для различных значений мощности оптического излучения, подаваемого на светодиод (АЛ118), были получены нагрузочные характеристики в фотовольтаическом режиме, т.е. измерены значения тока и напряжения при различных сопротивлениях нагрузки. Полученные данные отражены на рис. 2,a. Эти данные также могут быть интерпретированы как зависимость КПД преобразования от сопротивления

Письма в ЖТФ, 2018, том 44, вып. 8 

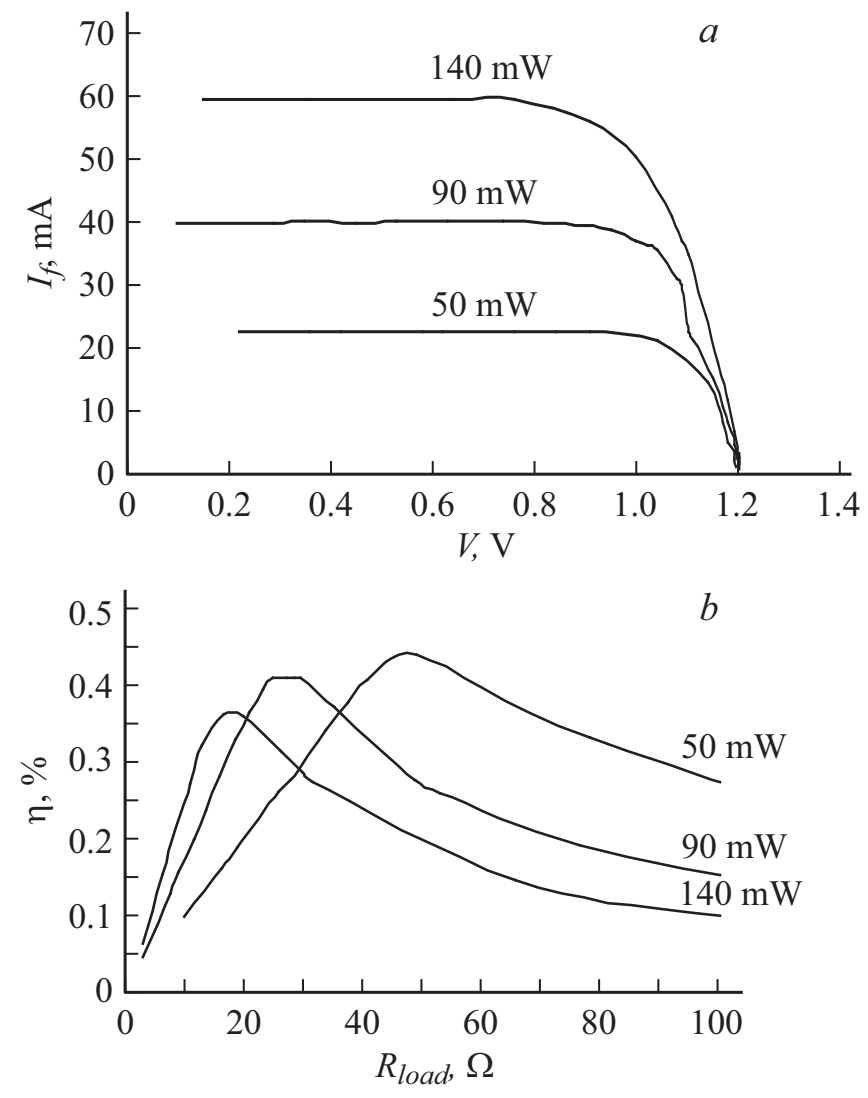

Рис. 2. Вольт-амперные $(a)$ и нагрузочные $(b)$ характеристики светодиодов АЛ118 при работе в фотовольтаическом режиме.

нагрузки (рис. $2, b$ ). Как видно из рис. $2, b$, КПД достигает максимального значения $(>45 \%)$ при определенном сопротивлении нагрузки и мощности оптического излучения. Заметим также, что при уменьшении мощности оптического излучения наблюдается повышение КПД и смещение положения максимума КПД в сторону бо́льших значений сопротивления нагрузки.

Письма в ЖТФ, 2018, том 44, вып. 8 
Максимальный КПД преобразования $\eta$ можно оценить по формуле

$$
\eta=k \frac{V_{o c} I_{s c}}{P_{0}}
$$

где $V_{o c}$ - напряжение холостого хода, $I_{s c}$ - ток короткого замыкания, $P_{0}$ - мощность оптического излучения, $k-$ коэффициент заполнения.

Для исследованных светодиодов в фотовольтаическом режиме коэффициент заполнения $k \approx 0.8$. Токи короткого замыкания при падающей оптической мощности $50 \mathrm{~mW}$ достигают $26 \mathrm{~mA}$, что обеспечивает КПД фотовольтаического преобразования до 50\%. Это соизмеримо с характеристиками фотоэлектрических преобразователей на основе структур, изготовленных в [5].

При мощности излучения 500-600 mW ток короткого замыкания на некоторых фотовольтаических преобразователях достигал $150 \mathrm{~mA}$, что при КПД около 15\% позволяет питать достаточно энергоемкие электронные устройства.

Таким образом, показано, что полупроводниковые структуры $\mathrm{Al}_{x} \mathrm{Ga}_{1-x} \mathrm{As}$, используемые для изготовления светодиодов, могут применяться также для изготовления фотовольтаических преобразователей монохроматического излучения с достаточно высоким КПД. Достоинством таких фотовольтаических элементов является высокое (более $1.2 \mathrm{~V}$ ) напряжение холостого хода, что позволяет питать некоторые электронные устройства без применения дополнительных повышающих преобразователей. КПД фотовольтаического преобразования можно существенно (до > 60\%) увеличить при оптимизации формы внешних электродов [6] и просветлении структуры. Изготовление на основе светодиодных структур фотовольтаических преобразователей с большой $\left(1-10 \mathrm{~mm}^{2}\right)$ площадью позволит снизить плотность оптической мощности, увеличить рабочий ток и значительно увеличить надежность и ресурс их работы.

\section{Список литературы}

[1] Клайн Б.Р. Оптическая система электропитания для электронных схем с использованием одного фотогальванического элемента. Патент РФ 2431915. Публ. 20.10.2011.

[2] Задворнов С.A. Исследование методов построения гибридных волоконнооптических измерительных систем. Автореф. канд. дис. М.: Ин-т радиотехники и электроники РАН (Фрязинский филиал), 2009. 22 с.

Письма в ЖТФ, 2018, том 44, вып. 8 
[3] Соколовский A.A. Микрооптические элементы и устройства для волоконнооптических измерительных систем. Автореф. докт. дис. М.: Ин-т радиотехники и электроники (Фрязинский филиал), 2009. 39 с.

[4] Dumke M., Heiserich G., Franke S., Schulz L., Overmeyer L. // J. Syst. Cybernet. Inform. 2010. V. 8. N 1. P. 55-60.

[5] Андреев В.М. // Соврем. электроника. 2014. № 6. С. 20-25.

[6] Algora C., Diaz V. // IEEE Trans. Electron Dev. 1998. V. 45. N 9. P. 2047-2054. 